REVIEW ARTICLE

\title{
Bioprobes for Investigating Mammalian Cell Cycle Control
}

\author{
HiROYUKI OSADA \\ The Institute of Physical and Chemical Research (RIKEN), \\ Wako-shi, Saitama 351-0189, Japan
}

(Received for publication July 10, 1998)

\begin{abstract}
Bioprobes are low molecular weight compounds which are useful for investigating mammalian cell functions. The use of bioprobes has substantially assisted the investigation of complex biochemical processes of the mammalian cell cycle. In this review, cell cycle inhibitors mainly isolated from the microorganism are described and their possibility as an antitumor agents is considered. Most cancer cells have some abnormality in the control mechanism of cell cycle progression. Cyclin-dependent kinases $(\mathrm{Cdk})$, which are activated by the binding with the cyclin and simultaneously by the phosphorylation/dephosphorylation of itself, play important roles as engines in the cell cycle. Tubulins are considered to be one of the most important proteins of the cell division machinery. Therefore, Cdk inhibitors and tubulin binders are possible anticancer drugs. Since the function of proteins controlling the cell cycle is also regulated by phosphorylation and dephosphorylation, inhibitors of protein kinases and phosphatases are considered as possible an antitumor agents. We expect that some bioprobes will be developed for clinical use.
\end{abstract}

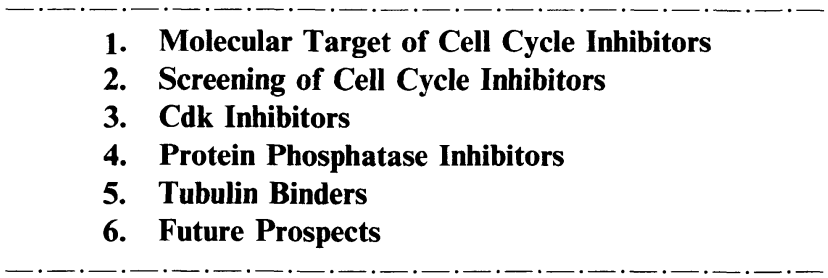

The rapid advances made in the study of the molecular basis of mammalian cell proliferation in the past few years have enabled us to develop new screening systems for isolating specific inhibitors of the mammalian cell cycle from microbial sources. We propose the new terminology, "bioprobes", which are naturally occurring compounds and their derivatives useful for investigating mammalian cell function. The use of bioprobes has substantially assisted the investigation of complex biochemical processes. There have been many reports on the isolation of new compounds regulating the cell cycle as well as on the identification of the molecular targets in mammalian cells of newly isolated bioprobes ${ }^{1 \sim 5 \text { ) }}$.

The cell cycle of normal mammalian cells is a strictly regulated process that responds to conditions in the body. Malignant cancer cells proliferate without regulation by the environment and spread throughout the body. Therefore, cell cycle inhibitors and metastasis inhibitors are considered as possible candidates for new anticancer drugs. In this review, the development of the antitumor bioprobes which block the cell cycle and the mechanism of action of the bioprobes are described.

\section{Molecular Target of Cell Cycle Inhibitors}

Cell cycle means the process where one mother cell divides into two daughter cells. It takes about 24 hours for one round of the cell cycle in normal human cells. The cell cycle is periodically classified into the following 4 stages: $G_{1}, S, G_{2}$ and $M$ (Fig. 1). DNA is replicated in the $S$ phase and the replicated DNA is 
Fig. 1. Mammalian cell cycle.

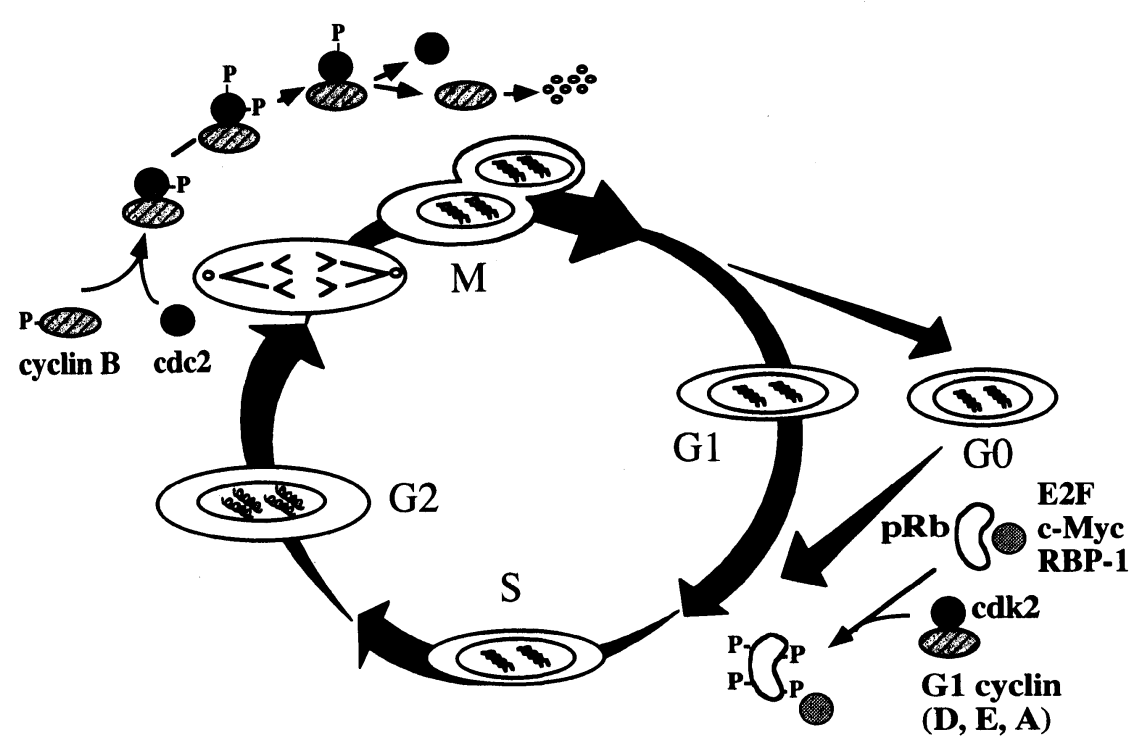

The cell cycle is regulated by a series of protein kinases and phosphatases which are also regulated by other proteins.

divided into daughter cells in the $M$ phase. The $G_{1}$ and $\mathrm{G}_{2}$ phases are the preparation periods for transition into $\mathrm{S}$ and $\mathrm{M}$ phases, respectively, and in both phases, $\mathrm{Cdk} /$ cyclin complexes play important roles as driving machinery for cell cycle progression ${ }^{6,7)}$.

During the $G_{1}$ phase, the cells sense environmental condition and prepare for DNA synthesis $\left(\mathrm{G}_{1}\right.$ checkpoint). If the preparation is completed, Cdk4 and cyclin $\mathrm{D}$ complex phosphorylate $\mathrm{Rb}$ protein $(\mathrm{pRb})$, which is a gene product of the retinoblastoma (RB) gene $^{8 \sim 10}$. The $\mathrm{Rb}$ protein was originally identified as an antioncogenic factor and is now recognized as a suppressor of cell cycle progression at the $G_{0} / G_{1}$ phase. In the $G_{0} / G_{1}$ phase, $\mathrm{pRb}$ interacts specifically with several cellular proteins, including the transcription factor E2F and protooncogene product $\mathrm{Myc}^{11 \sim 13)}$. After the phosphorylation by $\mathrm{Cdk} 4 /$ cyclin $\mathrm{D}, \mathrm{pRb}$ is further phosphorylated by $\mathrm{Cdk} 2 /$ cyclin $\mathrm{E}$ complex. The highly phosphorylated $\mathrm{pRb}$ loses its cell cycle suppression activity, and the cells proceed into the $\mathrm{S}$ phase ${ }^{14)}$. There is another checkpoint in the $G_{2}$ phase $\left(G_{2}\right.$ checkpoint), which evaluates DNA integrity and cell volume by unknown mechanism. After preparation, Cdc2/cyclin B complex is activated and cells progress into the $M$ phase. These checkpoints suppress the activation of the $\mathrm{Cdk} /$ cyclin complexes in normal cells. On the contrary, these checkpoints do not work in cancer cells ${ }^{15}$. According to recent analysis, ectopic expression of cyclin $D_{1}$ induces phosphorylation of $\mathrm{pRb}$ and accelerates progression at the $\mathrm{G}_{1}$ phase $^{16)}$. In addition, microinjection of either anti-cyclin $D_{1}$ antibodies or antisense plasmids prevents cells from entering the $S$ phase ${ }^{17)}$. From such a viewpoint, it is expected that the cell cycle of the malignant cancer cells is stopped by the driving machinery inhibitors, which block the activity of $\mathrm{Cdk} /$ cyclin complexes.

DNA is synthesized in the $\mathrm{S}$ phase. In the $\mathrm{S}$ phase, the nucleosome structure is modified to allow DNA to be replicated; therefore, a part of the single stranded DNA is exposed. Naked DNA strands are sensitive to DNA attacking compounds, such as bleomycin, neocarzinostatin, and cyclophosphamide ${ }^{18 \sim 20}$. Enzymes for DNA replication such as DNA polymerase are the target candidate to be inhibited ${ }^{19}$. Indeed, aphidicolin is a specific inhibitor of DNA polymerase $\alpha^{21)}$. The replicated DNA is condensed to form chromosomes and then divided into two daughter cells in the $\mathrm{M}$ phase.

In the $M$ phase, a series of most dynamic changes is observed such as the condensation of the chromosome, disappearance of the nuclear membrane, and distribution of the chromosome into two daughter cells. The function of DNA topoisomerases is required for proper chromosome condensation and failure of the condensation leads to missegregation of chromosomes. Etoposide and camptothecin affect DNA topoisomerases and inhibit the correct DNA distribution ${ }^{22)}$. The most 
important part of the machinery for chromosome division is the mitotic spindle. It consists of large numbers of short microtubules that surround each centrosome. As mitosis proceeds, the elongating ends of the microtubules attach to the chromosomes at each kinetochore and align the chromosomes in a metaphase plate. If this alignment is disrupted by irregular microtubules, mitosis is arrested. Vinblastine and taxol directly interact with tubulin ${ }^{23)}$ and arrest the cell cycle at the $\mathbf{M}$ phase. Thus, a drug which disrupts the microtubule array is useful in the treatment of malignant tumors which show rapid and abnormal cell proliferation. Indeed, some of the most useful cancer therapeutic agents are microtubule inhibitors, such as vinblastine and taxol ${ }^{24,25)}$. These compounds inhibit microtubule assembly and disassembly, respectively. The drugs which inhibit DNA replication or chromosome distribution are used as antitumor agents which block tumor cell growth. Moreover, these cell cycle inhibitors are useful for investigation of cell cycle regulation mechanism in mammalian cells.

\section{Screening of Cell Cycle Inhibitors}

We have established a bioassay system to find cell cycle inhibitors using a mouse temperature-sensitive mutant cell line, tsFT210, which has a defect in the cdc2 gene $^{5,26)}$ (Fig. 2). When cultured at the high, restrictive temperature, of $39.4^{\circ} \mathrm{C}$, tsFT210 cells are arrested at the $\mathrm{G}_{2}$ phase and become large in size. The microbial extract is added to the cells, simultaneously lowering the temperature to $32^{\circ} \mathrm{C}$. Four hours after release from $\mathrm{G}_{2}$ arrest, the cells enter into the $G_{1}$ phase. At this time, $G_{1}$ phase cells are easily discriminated from $G_{2} / M$ cells by their size under microscopic observation. If the test sample inhibits cell cycle progression at $G_{2}$, the increase of the $G_{1}$ cells is inhibited. The cell-morphology-based bioassay utilizing tsFT210 cells is very simple and sensitive for detecting $\mathrm{Cdc} 2$ kinase inhibitors and also $\mathrm{G}_{2} / \mathrm{M}$ phase inhibitors of the mammalian cell cycle. Using the bioassay system, we screened cell cycle inhibitors from microbial sources and discovered several inhibitors including novel compounds such as tryprostatins $A$ and $B^{27 \sim 31)}$. Thus, this bioassay allowed the detection of cell cycle inhibitors and provided a convenient and useful method for the screening of new inhibitors from microorganisms.

\section{Cdk Inhibitors}

As described in the previous section, cdk4 or cdk2 forms complexes with the $G_{1}$ cyclin and phosphorylate
Fig. 2. Bioassay to detect cell cycle inhibitors from microbial metabolites.
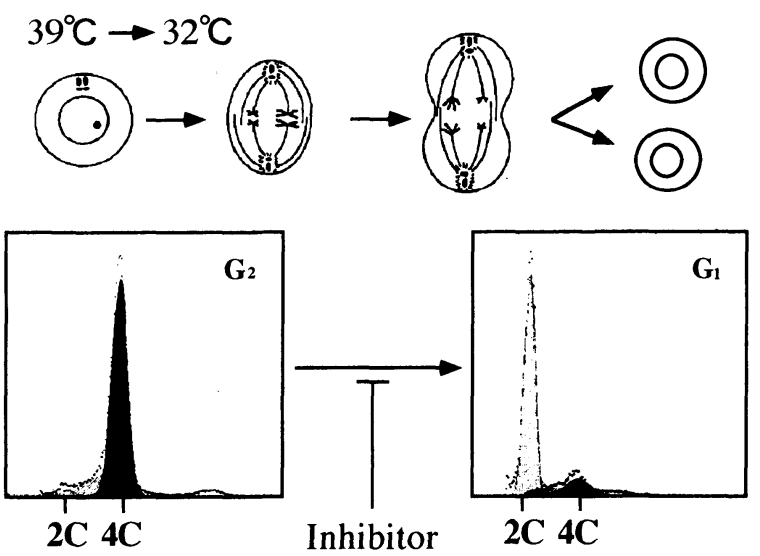

tsFT2 10 cells are arrested at the $\mathrm{G}_{2}$ by the culture at non-permissive temperature, $39^{\circ} \mathrm{C}$. Since the $\mathrm{G}_{2}$ cells contain a double amount of DNA and are large in size, it is easy to discriminate the $G_{2}$-cells from the $S$-cells or $\mathrm{G}_{1}$-cells by flow cytometry or microscopic observation. Screening samples are added to the culture of tsFT210 cells simultaneously with the release from the $\mathrm{G}_{2}$ arrest. If a sample has the cell cycle inhibition activity, the cell cycle remains at the $G_{2}$ or $M$ phase.

the $\mathrm{Rb}$ protein, which enables cell cycle progress from the $G_{1}$ to $S$ phase. Compounds that inhibit cdk activity and arrest cells at a specific point in the cell cycle have proven to be extremely useful tools for unravelling cell cycle regulatory events and might be useful for cancer chemotherapy.

KITAGaWA et al. reported that butyrolactone $\mathrm{I}$ is a selective inhibitor both of Cdk2 and Cdc2, but scarcely inhibits C-kinase, A-kinase, casein kinase, MAP kinase or EGF receptor-tyrosine kinase ${ }^{32)}$. Butyrolactone I inhibited phosphorylation of $\mathrm{pRb}$ catalyzed by cyclin A-Cdk2 and inhibited cell cycle progression from the $G_{1}$ to $\mathrm{S}$ phase in WI-38 cells. It also inhibited the activity of Cdc2 kinase (histone $\mathrm{H} 1$ kinase) and arrested cells at the $\mathrm{G}_{2}$ phase.

We have found several protein kinase inhibitors structurally related to staurosporine $\mathrm{e}^{33 \sim 35}$ (Fig. 3). These compounds show broad inhibition spectra of protein kinases including protein kinase $\mathrm{C}$ and $\mathrm{Cdc} 2$ kinase. Human K-562 leukemia cells are sensitive to these inhibitors and arrested at the $\mathrm{G}_{2}$ phase.

Phosmidosine (Fig. 4) had been isolated as an antifungal agent in our laboratory ${ }^{36}$. Recently, we reported that phosmidosine inhibits the cell cycle of the mammalian cells at the $G_{1}$ phase ${ }^{37,38}$. In addition, it was found that the synthesis of cyclin $D_{1}$ was inhibited 
Fig. 3. Structures of staurosporine related compounds.

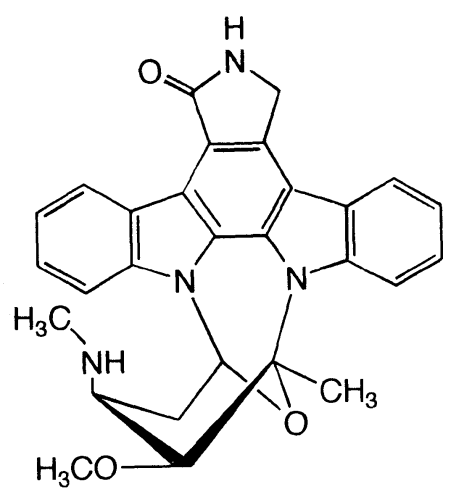

Staurosporine

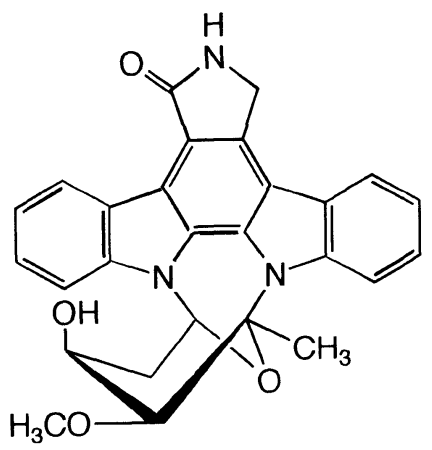

RK-286C<smiles></smiles>

RK-1409 (7-Oxostaurosporine)

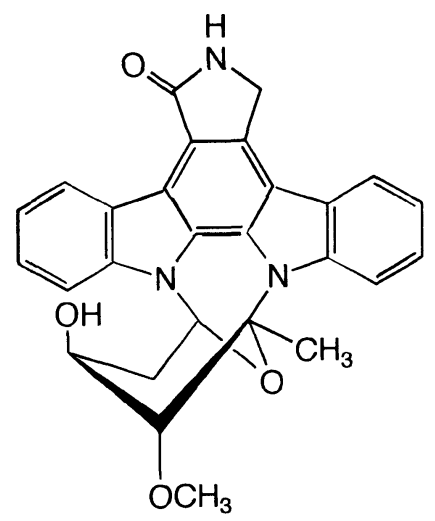

RK-1409B
Fig. 4. Phosmidosine<smiles></smiles>

by phosmidosine treatment in WI-38 human fibroblast. When cyclin $\mathrm{D}_{1}$ concentration is low, cdk4 and cdk2 activities are too weak to phosphorylate the $\mathrm{Rb}$ protein. Since the phosphorylation of $p R B$ is essential for the $G_{1}$ to $\mathrm{S}$ transition, phosmidosine blocks the cell cycle at the $G_{1}$ phase by suppression of cyclin $D_{1}$ expres$\operatorname{sion}^{38)}$ (Fig. 5).

\section{Protein Phosphatase Inhibitors}

Protein phosphatases are categorized into three groups based on their substrate specificity: protein serine/ threonine phosphatases (PPase), protein tyrosine phosphatases (PTPase) and dual specificity phosphatases (DSPase $)^{39)}$. Recently, it was reported that PTPase and DSPase are key enzymes in the signal transduction pathway for a wide range of cellular processes. $\mathrm{Cdc} 25^{40}$ ) and MKP-1 (3CH134) ${ }^{41)}$ are known to be DSPase involved in cell cycle regulation and response to growth factor stimulation, respectively. A specific inhibitor of DSPase would be a valuable tool to reveal signal transduction. Therefore, we used $\mathrm{VHR}^{42)}$, a human homologue of vaccinia viral VH1, as a target phosphatase to be inhibited by microbial metabolites for the screening. VHR expressed in bacteria had stronger dephosphorylation activity in vitro on $p \mathrm{Npp}$ (approximately 100fold) than bacterially expressed $\mathrm{Cdc} 25 \mathrm{~B}$. 
Fig. 5. Schematic model of the cell cycle arresting point of phosmidosine.

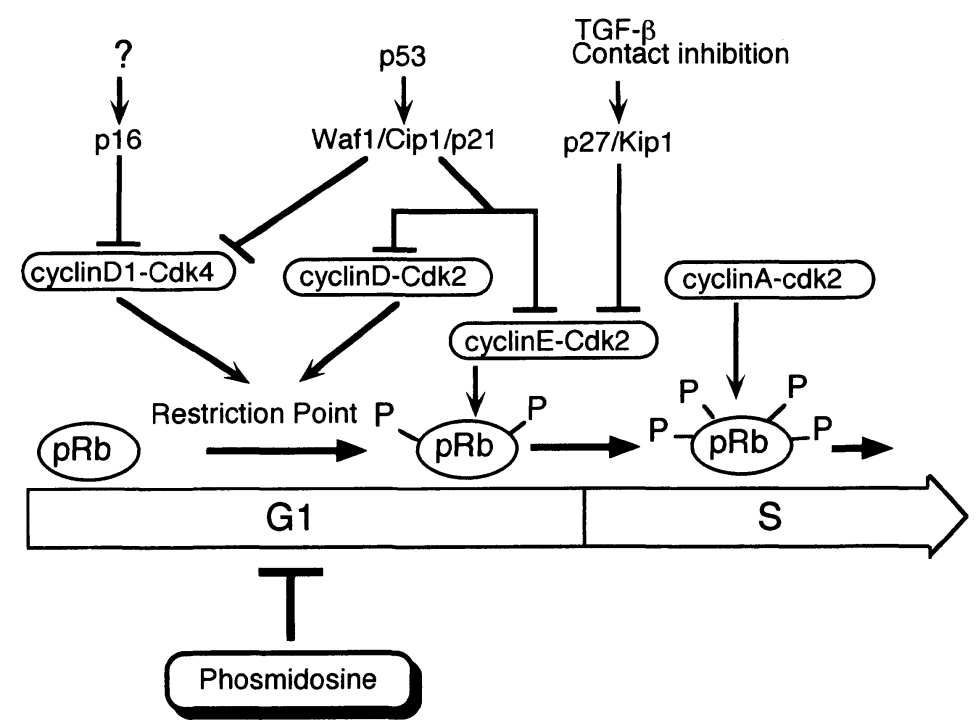

Phosmidosine suppressed cyclin $D_{1}$ protein levels and the phosphorylation of $p R B$ in response to mitogen stimulation and irreversibly arrested the cell cycle in $G_{1}$.

During screening, we isolated RK-682 (Fig. 6) as a DSPase inhibitor from the culture broth of Streptomyces $\mathrm{sp}^{43)}$. The chemical structure of RK-682 was already described as a phospholipase inhibitor ${ }^{44)}$ or as an HIV protease inhibitor ${ }^{45)}$ by other researchers. However, the concentration of RK-682 required for the inhibition of VHR activity was lower than the concentrations for phospholipase and HIV protease. RK-682 consists of a tetronic acid and a saturated fatty acid moiety. RK-682 derivatives showed different inhibitory activity on various phosphatases, such as VHR, Cdc25, CD45 and so on ${ }^{46)}$.

Vanadate is a well-known and useful inhibitor for investigation of the role of PTPase in eukaryotic cells ${ }^{47)}$. However, we found noticeable differences between vanadate and RK-682. For example, RK-682 was a more potent inhibitor (approximately 20 -times stronger) than vanadate against VHR. Furthermore, RK-682 and vanadate had different arrest points on cell cycle progression via different inhibition of the dephosphorylation of $\mathrm{Cdk} 2$ and $\mathrm{Cdc} 2$ as follows. In mammalian cell cycle progression, $G_{1} / S$ and $G_{2} / M$ transition are regulated by $\mathrm{Cdk} 2$ and $\mathrm{Cdc} 2$ activities, respectively. The Cdk4-cyclin E complex is essential during the $\mathrm{S}$ phase for phosphorylation of $\mathrm{Cdc} 25 \mathrm{~A}^{48)}$. Cdil (cyclin dependent kinase interactor) has a dual-specificity phosphatase activity and interacts with and negatively regulates Cdk2 ${ }^{49)}$. RK-682 inhibited the dephosphorylation of Cdk 2 catalyzed by another unidentified phosphatase and
Fig. 6. RK-682.<smiles>CCCCCCCCCCCCCCCCCCCO</smiles>

inhibits cell cycle progression at the $G_{1}$ phase. On the contrary, vanadate inhibits dephosphorylation of $\mathrm{Cdc} 2$ catalyzed by Cdc25B and inhibits cell cycle progression at the $\mathrm{G}_{2}$ phase. These observations indicate that each phosphatase inhibitor has a different specificity with respect to phosphatases.

Recently, we have isolated phosphatoquinones $\mathrm{A}$ and B (Fig. 7) from Streptomyces sp., which showed PTPase inhibitory activities with $\mathrm{IC}_{50}$ values of 28 and $2.9 \mu \mathrm{M}$, respectively ${ }^{50}$. Phosphatoquinones A and B are useful tool for investigating the role of PTPase in the signal transduction.

Stevastelins, isolated from the cultured broth of Penicillium sp. NK374186, are composed of valine, threonine, serine and a 3,5-dihydroxy-2,4-dimethylstearic acid moiety. Stevastelins have growth inhibition activity against OKT3-stimulated human T cell proliferation, but their biological properties have been not elucidated ${ }^{51}$. We found that some stevastelin derivatives (Fig. 8) inhibit the dephosphorylation activity of VHR and 
some inhibit cell cycle progression. To clarify the structure-activity relationships, we prepared a series of stevastelin derivatives and evaluated their inhibitory activities both on protein phosphatases and on the cell cycle. We found the functionality at the threonine residue to be important for their inhibitory activities ${ }^{52)}$.

Protein serine/threonine phosphorylation is a key regulation mechanism of the organization and dynamics of the actin cytoskeleton during cell motility, differentiation and cytokinesis. The level of the protein phosphorylation is dependent on the relative activities of both protein kinases and protein phosphatases. We examined the effect of phoslactomycin F (PLM-F) (Fig. 9), a protein phosphatase $2 \mathrm{~A}$ inhibitor, on the regulation of the cytoskeleton of NIH/3T3 fibroblasts ${ }^{53)}$. Treatment of cells with PLM-F induced actin filament depolymerization after 4 hours. This effect was reversible and actin filaments were reformed 1 hour after removal of the inhibitor. Results obtained from direct microinjec-

Fig. 7. Phosphatoquinone A and B.<smiles>CC(C)=CCC/C(C)=C/CC12OC1(C)C(=O)c1c(O)cc(O)cc1C2=O</smiles>

Phosphatoquinone $\mathrm{A}$<smiles>CC(C)=CCC/C(C)=C/CC1=C(C)C(=O)c2c(O)cc(O)cc2C1=O</smiles>

Phosphatoquinone $\mathrm{B}$ tion of PLM-F into cells suggested the concentration of PLM-F in the cell was lower than that in the medium. As PLM-F had no effects on polymerization of purified actin in vitro, PLM-F must induce actin depolymerization through an indirect mechanism. An in vitro assay showed that PLM-F inhibits protein phosphatase $2 \mathrm{~A}$ at a lower concentration $\left(\mathrm{IC}_{50}\right.$ about $3 \mu \mathrm{g} / \mathrm{ml}$ ) than it inhibits protein phosphatase 1. An in situ phosphorylation assay also revealed that PLM-F treatment stimulated the phosphorylation of intracellular vimentin. These results suggest that PLM-F is a specific inhibitor of protein phosphatase $2 \mathrm{~A}$, which is involved in the regulation of the organization of the actin cytoskeleton.

\section{Tubulin Binders}

The chromosomes of eukaryotic cells are distributed to daughter cells by a series of processes: condensation of DNA, elimination of the nuclear membrane, formation of the spindle and segregation of chromosomes. Microtubules play an important role in this process during the $M$ phase.

Microtubules consist of tubulin (mainly $\alpha$ and $\beta$ ) and various kinds of microtubule associated proteins (MAPs). Several proteins such as $\gamma$-tubulin exist at the microtubule organization center (it is called a central body in the animal cell and the spindle pole body in yeast). The microtubule stability depends on a balance of polymerization and disassembly of the tubulin, and the cell cycle stops when this balance collapses.

A number of tubulin-disassembling reagents have been reported, such as colchicine ${ }^{54)}$, vinblastine ${ }^{55)}$ and maytansine ${ }^{56}$. These are classified into three groups based on the binding kinetics to tubulin: the colchicine binding site, the vinca alkaloid binding site; and the maytansine-rhizoxin binding site. All these agents

Fig. 8. Stevastelin A and B.

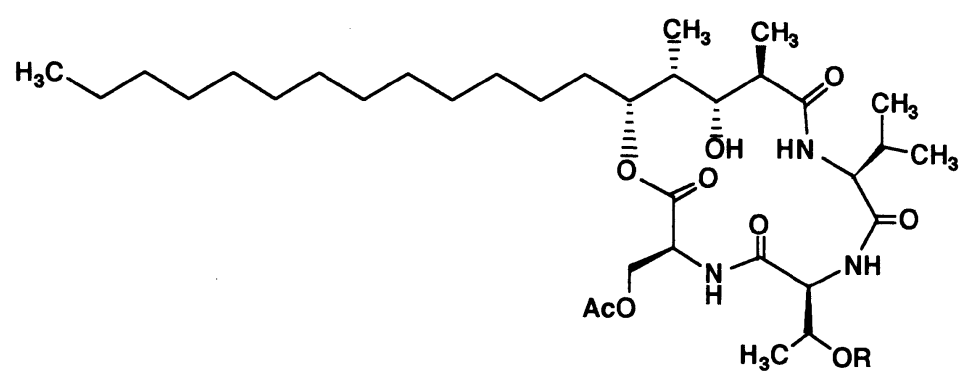


Fig. 9. Phoslactomycin F.<smiles>CCC(C)CCC(=O)OC1CCCC(/C=C\C=C/C(O)CC(OP(=O)(O)O)C(O)(/C=C/C2OC(=O)C=CC2CC)CCCN)C1</smiles>

directly bind to $\beta$-tubulin itself and inhibit the self-assembly of purified tubulin irrespective of the species of the assembly-inducers in vitro. These compounds might be useful cancer therapeutic agents.

Pironetin (Fig. 10) was originally isolated from the culture broth of Streptomyces sp. as a plant growth regulator and then a potent suppressor of the lymphocyte-blastogenesis ${ }^{57,58)}$. We have studied the biological effects of pironetin on cell cycle progression and its antitumor activity ${ }^{59)}$. At $10 \sim 20 \mathrm{ng} / \mathrm{ml}$, pironetin completely inhibits cell proliferation of $3 \mathrm{Y} 1$ cells. The cell cycle analysis revealed that pironetin arrested cell cycle progression at the $\mathbf{M}$ phase in a dosedependent manner. The antiproliferative effects of pironetin were also observed in the range of $20 \sim 50$ $\mathrm{ng} / \mathrm{ml}$ with several tumor cell lines. In CDF1-SLC mice bearing P388 leukemia cells, the intraperitoneal administration of $6.3 \mathrm{mg} / \mathrm{kg}$ pironetin over a 5-day period showed a moderate antitumor effect (T/C: $128 \%$ ). Since the chemical structure of pironetin is different from other $\mathbf{M}$ phase inhibitors such as colchicine or vinblastine, pironetin could be the lead compound for a potential new antitumor drug.

Tryprostatin A and B (TPS-A and TPS-B) (Fig. 11) were purified from the culture broth of Aspergillus fumigatus BM93960,61). TPS-A inhibited cell cycle progression of asynchronously cultured $3 \mathrm{Y} 1$ cells in the $M$ phase $^{62)}$. On the other hand, TPS-B (demethoxy analog of TPS-A) showed nonspecific cell cycle inhibition on cell growth even though it inhibited cell growth at a lower concentration than TPS-A. TPS-A treatment induced the reversible disruption of cytoplasmic microtubules of $3 \mathrm{Y} 1$ cells as observed by indirect immunofluorescence microscopy in the range of concentrations which specifically inhibit $\mathbf{M}$ phase progression. TPS-A also inhibited the in vitro assembly of microtubules which were purified from bovine brains;
Fig. 10. Pironetin and its derivatives.<smiles>C/C=C/C[C@H](C)[C@@H](O)[C@@H](C)[C@H](O)C[C@H]1OC(=O)C=C[C@H]1CC</smiles>

Pironetin : $\mathbf{R}=\mathrm{CH}_{3}$

Demethylpironetin : $\mathbf{R}=\mathbf{H}$<smiles>CC[C@H]1C=CC(=O)O[C@@H]1C[C@H](O)[C@@H](C)[C@H](OC)[C@@H](C)CC1OC1C</smiles>

Epoxypironetin

Fig. 11. Tryprostatin A and B.

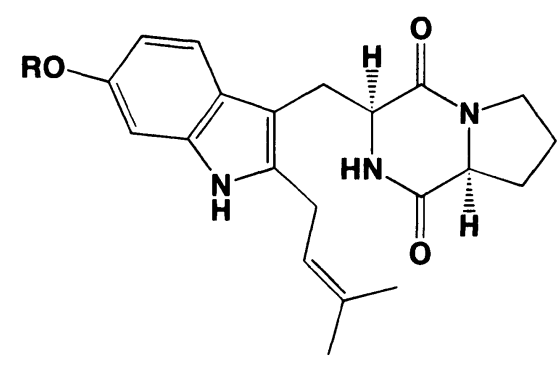

Tryprostatin A: $\mathbf{R =} \mathrm{CH}_{3}$ Tryprostatin $\mathbf{B}: \mathbf{R =} \mathbf{H}$

however, there was little or no effect on the self-assembly of purified tubulin when polymerization was induced by glutamate. TPS-A did not inhibit the assembly promoted by taxol, and by the digestion of the carboxyl-terminal domain of tubulin. On the contrary, TPS-A blocked tubulin assembly induced by the carboxyl-terminal domain interacting inducers, MAP2, tau and poly-Llysine. These results indicate that TPS-A is a novel inhibitor of MAP-dependent microtubule assembly and specifically inhibits cell cycle progression at the $\mathbf{M}$ phase by the disruption of the microtubule spindle ${ }^{62}$.

\section{Future Prospects}

Chemotherapy has assumed an increasingly important role in the management of patients with cancer. The employment of laboratory research on the biochemical 
and pharmacological actions of antitumor compounds should result in new leads that will permit future advances in the chemotherapy of tumors. This review describes aspects of the biochemical mechanism of action of some of the most important antitumor agents isolated in our laboratory.

Antitumor compounds including alkylating agents, platinum-containing compounds, folate antagonists, purine and pyrimidine nucleoside antimetabolites, and the anthracycline and bleomycin antibiotics were previously developed. Most of these antitumor compounds showed cell cycle inhibition activity on tumor cells. We have directly aimed to develop drugs which inhibit specific targets in cell cycle control. An objective of this review was to describe possible new biochemical targets and activities for novel bioprobes that are useful to investigate cell cycle mechanisms and might lead to the therapies of the future. These include cdk inhibitors, phosphatase inhibitors and tubulin binders to block cell cycle progression. It is my expectation that bioprobes will be useful for future investigating the cell cycle regulating mechanisms and that such knowledge may assist in developing more efficacious antitumor compounds in the future.

\section{Acknowledgments}

A part of this review was given at the presentation of the Sumiki Umezawa Memorial Award. I should like to express my sincere thanks to Prof. KIYOsHI Isono who guided my research. The efforts of all my collaborators are gratefully acknowledged.

\section{References}

1) Usui, T.; M. Yoshida, K. Abe, H. Osada, K. Isono \& T. BEPPU: Uncoupled cell cycle without mitosis induced by a protein kinase inhibitor, K-252a. J. Cell Biol. 115: $1275 \sim 1282,1991$

2) Aвe, K.; M. Yoshida, T. Usui, S. Horinouchi \& T. BEPPU: Highly synchronous culture of fibroblasts from G2 block caused by staurosporine, a potent inhibitor of protein kinases. Exp. Cell Res. 192: 122 127, 1991

3) Gadbois, D. M.; J. R. Hamaguchi, R. A. Swank \& E. M. BRADBURY: Staurosporine is a potent inhibitor of p34 $4^{\mathrm{cdc} 2}$ and p34 ${ }^{\mathrm{cdc} 2}$-like kinases. Biochem. Biophys. Res. Commun. 184: 80 85, 1992

4) Meijer, L.: Chemical inhibitors of cyclin-dependent kinases. Trend. Cell Biol. 6: 393 397, 1996

5) Osada, H.; C.-B. CuI, R. OnOSE \& F. HanaOKa: Screening of cell cycle inhibitors from microbial metabolites by a bioassay using a mouse cdc2 mutant cell line, tsFT210. Bioorg. Med. Chem. 5: 193 203, 1997

6) Murray, A. W.: Creative blocks: cell-cycle checkpoint and feedback controls. Nature 359: 599 604, 1992

7) Serrano, M.; G. J. Hannon \& D. Beach: A new regulatory motif in cell-cycle control causing specific inhibition of cyclin D/CDK4. Nature 366: 704 707, 1993

8) Marshall, C. J.: Tumor suppressor genes. Cell 64: $313 \sim 326,1991$

9) Zhou, W.; N. Takuwa, M. Kumada \& Y. Takuwa: Protein kinase $\mathrm{C}$-mediated bidirectional regulation of DNA synthesis, RB protein phosphorylation, and cyclindependent kinases in human vascular endothelial cells. J. Biolog. Chem. 268: $23041 \sim 23048,1993$

10) RileY, D. J.; E. Y.-H. P. LeE \& W. LeE: The retinoblastoma protein: more than a tumor suppressor. Ann. Rev. Cell Biol. 10: 1 29, 1994

11) Rustgi, A. K.; N. Dyson \& R. Bernards: Aminoterminal domains of c-myc and N-myc proteins mediate binding to the retinoblastoma gene product. Nature 352 : $541 \sim 544,1991$

12) Chellapan, S. P.; S. Hiebert, M. Mudryj, J. M. Horowitz \& J. R. Nevins: The E2F transcription factor is a cellular target for the RB protein. Cell 65: 1053 1061, 1991

13) CaO, L.; B. Faha, M. Dembski, L. Tasai, E. Harlow \& $\mathrm{N}$. Dyson: Independent binding of the retinoblastoma protein and p107 to the transcription factor E2F. Nature 355: 176 179, 1992

14) Resnitzky, D.; M. Gossen, H. Bujard \& S. I. Reed: Acceleration of the $\mathrm{G} 1 / \mathrm{S}$ phase transition by expression of cyclins D1 and E with an inducible system. Mol. Cell Biol. 14: 1669 1679, 1994

15) Poon, R. Y.; M. S. Chau, K. Yamashita \& T. Hunter: The role of Cdc2 feedback loop control in the DNA damage checkpoint in mammalian cells. Cancer Res. 57: 5168 5178, 1997

16) Quele, D. E.; R. A. Ashmun, S. J. Shurtlef, J. Hato, D. B.-SAGi, M. F. Roussel \& C. J. SHERR: Overexpression of mouse D-type cyclins accelerates $\mathrm{G} 1$ phase in rodent fibroblasts. Genes. Develop. 7: 1559 1571, 1993

17) Baldin, V.; J. Lukas, M. J. Marcote, M. Pagano \& G. DraetTA: Cyclin D is a nuclear protein required for cell cycle progression in G1. Genes Develop. 7: 812 821, 1993

18) BeERman, T. A.; R. PoOn \& I. H. Goldberg: Single-strand nicking of DNA in vitro by neocarzinostatin and its possible relationship to the mechanism of drug action. Biochim. Biophys. Acta 475: $294 \sim 306,1977$

19) Muller, W. E.; A. Maidhof, J. Arendes, W. Geurtsen, R. K. ZAHN \& R. SCHMIDSEDER: Additive effects of bleomycin and neocarzinostatin on degradation of DNA, inhibition of DNA polymerase beta, and cell growth. Cancer Res. 39: 3768 3773, 1979

20) Takeshita, M.; L. S. Kappen, A. P. Grollman, M. EISENBERG \& I. H. GoldberG: Strand scission of deoxyribonucleic acid by neocarzinostatin, auromomycin, and bleomycin: studies on base release and nucleotide sequence specificity. Biochemistry 20: 7599 7606, 1981

21) Ikegami, S.; T. Taguchi, M. Ohashi, M. Oguro, H. NaGano \& Y. Mano: Aphidicolin prevents mitotic cell division by interfering with the activity of polymerasealpha. Nature 275: 458 460, 1978

22) TsaO, Y.-P.; P. D'ArPa \& L. F. LiU: The involvement of active DNA synthesis in camptothecin-induced $\mathrm{G} 2$ arrest: Altered regulation of $\mathrm{p} 34^{\mathrm{cdc} 2} /$ cyclin B. Cancer Res. 52: $1823 \sim 1829,1992$

23) Verde, F.; J.-M. Berrez, C. Antony \& E. Karsenti: 
Taxol-induced microtubule asters in mitotic extract of Xenopus eggs: requirement for phosphorylated factors and cytoplasmic dynein. J. Cell Biology 112: 1177 1187, 1991

24) Wilson, L.; K. M. Creswell \& D. Chin: The mechanism of action of vinblastine. Binding of [acetyl- ${ }^{3} \mathrm{H}$ ] vinblastine to embryonic chick brain tubulin and tubulin from sea urchin sperm tail outer doublet microtubules. Biochemistry 14: 5586 5592, 1975

25) Kumar, N.: Taxol-induced polymerization of purified tubulin. Mechanism of action. J. Biol. Chem. 256: 10435 10441, 1981

26) Mineo, C.; Y. Murakami, Y. Ishimi, F. Hanaoka \& M. YAMADA: Isolation and analysis of a mammalian temperature-sensitive mutant defective in G2 functions. Exp. Cell Res. 167: 53 62, 1986

27) Cui, C.-B.; H. Kakeya, G. OKada, R. Onose, M. Ubukata, I. TAKahashi, K. Isono \& H. Osada: Tryprostatins A and B, novel mammalian cell cycle inhibitors produced by Aspergillus fumigatus. J. Antibiotics 48: $1382 \sim 1384,1995$

28) Cui, C.-B.; H. KaKeYa \& H. Osada: Spirotryprostatin a novel mammalian cell cycle inhibitor produced by Aspergillus fumigatus. J. Antibiotics 49: 787 790, 1996

29) Cui, C.-B.; M. Ubukata, H. Kakeya, R. Onose, G. OKaDA, I. TAKahashi, K. IsONO \& $\mathrm{H}$. OSADA: Acetophthalidin, a novel inhibitor of mammalian cell cycle, produced by a fungus isolated from a sea sediment. J. Antibiotics 49: 216 220, 1996

30) Cui, C.-B.; H. KaKeya \& H. Osada: Novel mammalian cell cycle inhibitors, spirotryprostatins $\mathrm{A}$ and $\mathrm{B}$, produced by Aspergillus fumigatus, which inhibit mammalian cell cycle at G2/M phase Tetrahedron 52: $12651 \sim 12666$, 1996

31) CuI, C.-B.; H. Kakeya \& H. Osada: Novel mammalian cell cycle inhibitors, cyclotryprostatins A-D, produced by Aspergillus fumigatus, which inhibit mammalian cell cycle at G2/M phase. Tetrahedron 53: 59 72, 1997

32) Kitagawa, M.; H. Higashi, I. Suzuki-Takahashi, T. Okabe, H. Ogino, Y. Taya, S. Nishimura \& A. OKUYAMA: A cyclin-dependent kinase inhibitor, butyrolactone I, inhibits phosphorylation of RB protein and cell cycle progression. Oncogene 9: 2549 2557, 1994

33) Osada, H.; H. Takahashi, K. Tsunoda, H. Kusakabe \& K. IsONO: A new inhibitor of protein kinase C, RK-286C (4'-demethylamino-4'-hydroxystaurosporine). I. Screening, taxonomy, fermentation and biological activity. $\mathbf{J}$. Antibiotics 43: 163 167, 1990

34) Osada, H.; H. Koshino, T. Kudo, R. Onose \& K. Isono: A new inhibitor of protein kinase C, RK-1409 (7-oxostaurosporine). I. Taxonomy and biological activity. J. Antibiotics 45: 189 194, 1992

35) Koshino, H.; H. Osada, S. Amano, R. Onose \& K. Isono: A new inhibitor of protein kinase C, RK-1409B (4'demethylamino-4'-hydroxy-3'-epistaurosporine). J. Antibiotics 45: $1428 \sim 1432,1992$

36) Uramoto, M.; C. J. Kim, K. Shinya, H. Kusakabe \& K. ISONO: Isolation and characterization of phosmidosine a new antifungal nucleotide antibiotic. J. Antibiotics 44: 375 381, 1991

37) Matsuura, M.; R. Onose \& H. Osada: Morphology reversion activity of phosmidosine and phosmidosine $\mathrm{B}$, a newly isolated derivative, on src transformed NRK cells.
J. Antibiotics 49: $361 \sim 365,1996$

38) Kakeya, H.; R. Onose, P. C. Liu, C. Onozawa, F. Matsumura \& $\mathrm{H}$. Osada: Inhibition of cyclin D1 expression and phosphorylation of retinoblastoma protein by phosmidosine, a nucleotide antibiotic. Cancer Res. 58: 704 710, 1998

39) Walton, K. M. \& J. E. Dixon: Protein tyrosine phosphatases. Annu. Rev. Biochem. 62: $101 \sim 120,1993$

40) Dunphy, W. G. \& A. KumagaI: The $\operatorname{cdc} 25$ protein contains an intrinsic phosphatase activity. Cell 67: $189 \sim 196,1991$

41) Sun, H.; C. H. Charles, L. F. Lau \& N. K. Tonks: MKP-1 (3CH134), an immediate early gene product, is a dual specificity phosphatase that dephosphorylates MAP kinase in vivo. Cell 75: 487 493, 1993

42) Ishibashi, T.; D. P. Bottaro, A. Chan, T. Miki \& S. A. AARONSON: Expression cloning of a human dualspecificity phosphatase. Proc. Natl. Acad. Sci. USA 89: $12170 \sim 12174,1992$

43) Hamaguchi, T.; T. Sudo \& H. Osada: RK-682, a potent inhibitor of tyrosine phosphatase, arrested the mammalian cell cycle progression at G1 phase. FEBS Lett. 372: $54 \sim 58,1995$

44) Shinagawa, S.; M. Muroi, R. Ito \& T. Hida: Tetronic acid derivatives. JP5-43568, 1993

45) Roggo, B. E.; F. Petersen, R. Delmendo, H.-B. Jenny, H. H. Peter \& J. Roesel: 3-Alkanoyl-5-hydroxymethyl tetronic acid homologue and resistomycin: New inhibitors of HIV-1 protease. J. Antibiotics 47: 136 142, 1994

46) Sodeoka, M.; R. SAmpe, T. Kagamizono \& H. Osada: Asymmetric synthesis of RK-682 and its analogs, and evaluation of their protein phosphatase inhibitory activities. Tetrahedron Lett. 37: 8775 8778, 1996

47) Imbert, V.; J.-F. Peyron, D. F. Far, B. Mari, P. AUBERGER \& B. Rossi: Induction of tyrosine phosphorylation and $\mathrm{T}$-cell activation by vanadate peroxide, an inhibitor of protein tyrosine phosphatases. Biochem. J. 297: $163 \sim 173,1994$

48) Terada, Y.; M. Tatsuka, S. Jinno \& H. Okayama: Requirement for tyrosine phosphorylation of Cdk4 in G1 arrest induced by ultraviolet irradiation. Nature 376: $358 \sim 362,1995$

49) Gyuris, J.; E. Golemis, H. Chertkov \& R. Brent: Cdil, a human $\mathrm{Gl}$ and $\mathrm{S}$ phase protein phosphatase that associates with cdk2. Cell 75: $791 \sim 803,1993$

50) Kagamizono, T.; T. Hamaguchi, T. Ando, K. Sugawara, T. Adach \& H. Osada: Phosphatoquinones A and B, novel ryrosine phosphatase inhibitors produced by Streptomyces sp. R7134. submitted to J. Antibiotics

51) Morino, T.; A. Masuda, M. Yamada, M. Nishimoto, T. NishiKioRi \& S. SAITO: Stevastelins, novel immunosuppressants produced by Penicillium. J. Antibiotics 47: $1341 \sim 1343,1994$

52) Hamaguchi, T.; A. Masuda, T. Morino \& H. Osada: Stevastelins, a novel group of immunosuppressants, inhibit dual-specificity protein phosphatases. Chemistry \& Biology 4: 279 286, 1997

53) Usui, T.; G. Marriott, M. InAGaki \& H. Osada: Phoslactomycin F: Another specific inhibitor of protein phosphatase 2A. submitted to J. Biochem.

54) Banerjee, A. C. \& B. Bhattacharyya: Colcemid and colchicine binding to tubulin. Similarity and dissimilarity. FEBS Lett. 99: 333 336, 1979 
55) Owellen, R. J.; A. H. Owens, Jr. \& D. W. Donigian: The binding of vincristine, vinblastine and colchicine to tubulin. Biochem. Biophys. Res. Commun. 47: 685 691, 1972

56) Fellous, A.; R. F. Luduena, V. Prasad, M. A. Jordan, W. ANDERSON, R. OHAYON \& P. T. Smith: Effects of Tau and MAP2 on the interaction of maytansine with tubulin: inhibitory effect of maytansine on vinblastine-induced aggregation of tubulin. Cancer Res. 45: 5004 5010, 1985

57) Kobayashi, S.; K. Tsuchiya, T. Harada, M. Nishide, T. Kurokawa, T. Nakagawa, N. Shimada \& $\mathrm{K}$. Kobayashi: Pironetin, a novel plant growth regulator produced by Streptomyces sp. NK10958. I. Taxonomy, production, isolation and preliminary characterization. $\mathbf{J}$. Antibiotics 47: 697 702, 1994

58) Kobayashi, S.; K. Tsuchiya, T. Kurokawa, T. Nakagawa, N. Shimada \& Y. ItTaKa: Pironetin, a novel plant growth regulator produced by Streptomyces sp. NK10958. II. Structural elucidation. J. Antibiotics 47:
$703 \sim 707,1994$

59) Kondoh, M.; T. Usui, S. Kobayashi, K. Tsuchiya, K. Nishikawa, T. Nishikiori, T. Mayumi \& H. Osada: Cell cycle arrest and antitumor activity of pironetin and its derivatives. Cancer Lett. 126: 29 32, 1998

60) CUI, C.-B.; H. KaKeYA \& H. OsadA: Novel mammalian cell cycle inhibitors, tryprostatins $\mathrm{A}, \mathrm{B}$ and other diketopiperazines produced by Aspergillus fumigatus. II. Physico-chemical properties and structures. J. Antibiotics 49: 534 550, 1996

61) Cui, C.-B.; H. KaKeya, G. OKada, R. Onose \& H. OSada: Novel mammalian cell cycle inhibitors, tryprostatins A, B and other diketopiperazines produced by Aspergillus fumigatus. I. Taxonomy, fermentation, isolation and biological properties, J. Antibiotics 49: 527 533, 1996

62) Usui, T.; M. Kondoh, C.-B. CuI, T. Mayumi \& H. Osada: Tryprostatin A, a specific and novel inhibitor of microtubule assembly. Biochem. J. 333: $543 \sim 548,1998$ 